\title{
Multicentre Controlled Comparative Trial of Clofazimine and Dapsone in Low Dosages
}

\author{
T. F. AHRENS \\ Biological Research Dept., Pharmaceuticals Division, CIBA-GEIGY Ltd, \\ Basle, Switzerland \\ and \\ J. H. S. PETTIT \\ 174, Jalan Tuanku Abdul Rahman, Kuala Lumpur, Malaysia \\ and \\ D. S. RIDLEY \\ Path. Hospital for Tropical Diseases St. Pancras Way, \\ London NW1 OPE, England \\ and \\ LUCIA GLAUS \\ Biometrical Unit, Pharmaceuticals Division,CIBA-GEIGY Ltd, \\ Basle, Switzerland
}

\begin{abstract}
A multicentric, controlled double-blind trial was undertaken to compare the efficacy of low-dosage therapy with dapsone and clofazimine in lepromatous leprosy. The results, which were evaluated centrally allow the conclusion that lowering of the dosage, either of dapsone or of clofazimine, is not followed by a proportional loss of antibacterial activity. The incidence of lepra reactions, especially ENL, in the clofazimine group was significantly lower and skin discolouration no worse than in the dapsone group. The use of clofazimine in low doses would appear to serve a useful purpose and is recommended for periods of up to one year.
\end{abstract}

\section{Introduction}

The therapeutic activity of clofazimine in human lepromatous leprosy, which was first reported by Browne and Hogerzeil in 1962, has been assessed in a large number of clinical investigations. By the end of 1974, about 250 papers on this subject, dealing altogether with more than 2000 patients, had been published.

\footnotetext{
* Requests for reprints should be addressed to Dr Ahrens.

Received for publication 26 May, 1975.
} 
The administration of clofazimine in daily doses of $300 \mathrm{mg}$ was found to produce discolouration of the skin. This proved less troublesome at a dose of $100 \mathrm{mg}$ twice weekly, and the results obtained in a few patien ts were otherwise comparable to those achieved in the initial phases of treatment with other anti-leprosy drugs (Waters, 1968). It remained to be seen whether this low dosage level would still exert an anti-inflammatory action, as had been suggested by Browne (1965) and others (Karat et al., 1970; Tolentino et al., 1971).

With dapsone, attempts to lower the dosage were originally prompted by the hope that this would decrease the incidence of erythema nodosum leprosum (E.N.L.). Short-term observations indicated that a dosage of $50 \mathrm{mg}$ of dapsone twice weekly elicited a satisfactory antibacterial effect (Pettit and Rees, 1967; Pearson and Pettit, 1969).

Accordingly, it was decided to compare the results of low-dose therapy with dapsone and clofazimine as regards both antibacterial activity and the incidence of reactions. In view of the well-known difficulties in finding a sufficient number of suitable patients in any single institution, a double-blind trial was planned on a multicentric basis. The protocol for this trial was ready in 1968, but the drawbacks inherent in the multicentre method delayed its completion until the end of 1973.

\section{Methods}

The following investigators co-operated in the multicentric double-blind clinical trial:

Dr P. N. Behl and Dr Bhatia, Delhi (India)

Dr D. S. Chaudhury, Elmina (Ghana) and Liteta (Zambia)

Dr T. F. Davey and Dr A. Butt, Dichpalli (India)

Dr Z. A. Fazelbhoy and Dr Daud, Karachi (Pakistan)

Dr M. Flowers and Dr B. L. Whitty, Chandraghona (Bangladesh)

Dr M. Harahap, Medan (Indonesia)

Dr M. Hermes, Mwena-Ndanda (Tanzania)

Dr B. Pérez P., Trillo (Spain)

Dr Rajagopalan, Johore Bahru (Malaysia)

Dr C. Reyes C., Mérida (Mexico)

Dr K. Robson, Mount Hagen (Papua, New Guinea)

Dr E. Rodríguez C., Asunción (Paraguay)

Dr R. B. W. Smith, Honiara (Solomon Islands)

Dr T. Smith, Chiang Mai (Thailand)

Dr R. Thakolkaran, Kozhukully (India)

Dr. A. G. Warren, Hay Ling Chau (Hong Kong)

\section{AIMS OF THE STUDY}

The main purpose was to compare the antibacterial effects of low dosages of dapsone $(50 \mathrm{mg})$ and clofazimine $(100 \mathrm{mg})$, both administered twice weekly, for a period of 48 weeks. The incidence and severity of any lepra reactions or skin pigmentation occurring in either of the two treatment groups were to be noted. 


\section{CRITERIA FOR ADMISSION AND EVALUATION}

The conditions of acceptance were that the patients should be male, over 12 years of age and suffering from active, purely lepromatous leprosy. They were also to be untreated cases or at least they were not supposed to have received any antileprosy treatment for the last 5 years. Patients suffering from other severe diseases in addition to leprosy in particular from tuberculosis or diseases requiring corticosteroid therapy, were excluded.

From the histological point of view, cases classified according to Ridley and Jopling $(1962,1970)$ as LL, including the sub-group LI (Ridley and Waters, 1969), were considered acceptable. All other classifications were excluded.

The histopathological index (HI), formerly known as LIB (Ridley, 1967; Ridley and Hilson, 1967) was determined, using the granuloma index (GI) as a factor, i.e. the fraction of the dermis accupied by granuloma in tenths. No cases showing a GI of less than 0.15 were considered for evaluation.

The bacteriological diagnosis was made on the basis of the bacterial index (BI) according to Ridley (1968), using a logarithmic scale from 0 to 6 , and the morphological index (MI), indicating the percentage of evenly and deeply staining Myco. leprae in skin scrapings (Waters and Rees, 1962). No cases with a MI of less than 5 , or a $\mathrm{BI}$ of less than 1.5 were included in the evaluation.

\section{PROCEDURES}

The 16 investigators listed above selected the patients according to a pre-established protocol. It was left to the investigator's discretion to withdraw a particular patient from the trial, if need be.

Clinical and bacteriological assessments were repeated at 6-weekly intervals throughout the period of treatment, and biopsies at 6-monthly intervals. The material for biopsies and smears was always taken from the same lesions. Biopsies were sent to London (D.S.R.), skin smears to Kuala Lumpur (J.H.S.P.) and clinical reports to Basle (T.F.A.). The appropriate examinations and evaluations of results were made at these centres.

The trial substances were supplied to the investigators in numbered bottles containing capsules of either $50 \mathrm{mg}$ dapsone or $10 \mathrm{mg}$ clofazimine, which were identical in appearance. Other material, including the fixative for the biopsies, was completely uniform. The allocation to treatment was randomized. Neither the investigators nor the present authors had knowledge about the key during the trial. There was, however, the possibility to have the code broken by an independent person in case of unwanted side effects. One of us (T.F.A.) took the responsibility for notifying the investigators of any unfavourable bacteriological or histological evolution that might make it necessary to stop the trial in the best interest of a particular patient.

\section{Description of the Treatment Groups}

Altogether 138 patients were selected in the 17 above-mentioned institutions for inclusion in the study. Of these, 44 proved primarily unsuitable, so that the population studied comprised in all 94 patients. Twenty-six of these were African, 51 Asian, 6 Melanesian, 4 Latin American and 7 European. The mean body weights ranged from $47.8 \mathrm{~kg}$ in Thai patients to $64.7 \mathrm{~kg}$ in Europeans. There was no significant difference between the two groups in respect of age. 
Histologically, the dapsone-treated patients 48 in total, were classified as LL in $15, \mathrm{LI}$ in 21 and BL in 12 cases. The distribution of the clofazimine-treated group ( $n=46)$ was 12 for LL, 23 for LI and 11 for BL.

The nature and distribution of lesions were recorded in detail but, for lack of space, are not presented here. It may be stated that both groups were fully comparable as to their clinical features, with the one exception that diffuse infiltrations were more frequent among the LL/LI patients within the clofazimine group than among the corresponding cases of the dapsone-group. This difference was statistically significant.

As could be foreseen, the number of patients in both treatment groups diminished continuously during the trial. The rate of this process was about equal in both groups: the dapsone group initially comprised 48 patients; after 24 weeks there were 35 , and by the end of the trial, after 48 weeks, 27 . The respective numbers for the clofazimine-treated group were 46, 34 and 22 patients. Prolongation of the trial beyond the first year took place only in 4 patients, thus not allowing statistical analysis.

\section{Results}

In the following description of the bacterial and histopathological results, only the LL and LI patients are considered. BL patients, however, were taken into consideration together with the former for the evaluation of side effects and lepra reactions.

\section{BACTERIAL FINDINGS}

The bacteriological findings made at start of trial and during therapy with the two trial drugs are shown in Table 1. In both treatment groups, there was a significant decrease in the MI, which was practically zero by the 18 th week. The decrease in the $\mathrm{BI}$-as was to be expected-was slower.

TABLE 1

Bacteriological findings in evaluable LL/LI patients at the beginning of and during treatment

\begin{tabular}{|c|c|c|c|c|c|c|c|c|}
\hline \multirow{3}{*}{ Week } & \multicolumn{4}{|c|}{ Dapsone } & \multicolumn{4}{|c|}{ Clofazimine } \\
\hline & \multicolumn{2}{|r|}{ BI } & \multicolumn{2}{|r|}{ MI } & \multicolumn{2}{|r|}{ BI } & \multicolumn{2}{|r|}{ MI } \\
\hline & $n$ & $\bar{x}$ & $n$ & $\bar{x}$ & $n$ & $\bar{x}$ & $n$ & $\overline{\mathrm{x}}$ \\
\hline 0 & 25 & 3.648 & 16 & 15.225 & 22 & 3.714 & 14 & 17.493 \\
\hline 6 & 21 & 3.300 & 14 & 6.450 & 18 & 3.567 & 11 & 3.609 \\
\hline 12 & 22 & 3.427 & 14 & 1.720 & 22 & 3.450 & 12 & 3.800 \\
\hline 18 & 19 & 3.447 & 12 & 0.208 & 19 & 3.363 & 8 & 0.338 \\
\hline 24 & 21 & 3.257 & 13 & 0.085 & 20 & 3.140 & 11 & 0.136 \\
\hline 30 & 5 & 2.900 & 4 & 0.100 & 8 & 3.775 & 6 & 0.200 \\
\hline 36 & 17 & 3.412 & 10 & 0.015 & 16 & 3.244 & 8 & 0.063 \\
\hline 42 & 3 & 4.167 & 2 & 0.100 & 3 & 3.733 & 4 & 0.075 \\
\hline 48 & 14 & 3.079 & 8 & 0.025 & 16 & 2.725 & 8 & 0.038 \\
\hline Initial ranges & \multicolumn{2}{|c|}{$1.7-4.7$} & \multicolumn{2}{|c|}{$5.5-28.0$} & \multicolumn{2}{|c|}{$1.5-4.8$} & \multicolumn{2}{|c|}{$5.3-49.0$} \\
\hline $\begin{array}{l}\text { Regression coefficient } \\
\text { for week } 0-18, b_{c}=\end{array}$ & & & \multicolumn{2}{|c|}{-0.063} & & & \multicolumn{2}{|c|}{-0.055} \\
\hline $\begin{array}{l}\text { Regression coefficient } \\
\text { for week } 0-48, b_{c}=\end{array}$ & \multicolumn{2}{|c|}{-0.010} & & & \multicolumn{2}{|c|}{-0.02} & & \\
\hline
\end{tabular}


The decrease in the bacteriological indices was expressed by means of the linear regression coefficients, which were compared statistically for the two treatment groups. A method proposed by Bliss (1967) was used to combine the individual regression lines. In the regression analysis of the $\mathrm{MI}$, only the obviously linear part of the semilogarithmic curve was taken into consideration, i.e. the section relating to the first 18 weeks of treatment. The analysis of both the MI and the $\mathrm{BI}$ does not show a statistically significant difference between the two treatment groups.

\section{HISTOPATHOLOGICAL FINDINGS}

Only those patients were assessed histologically whose lesions showed sufficient activity at the beginning. Subsequently, the activity of the lesions was classified as "regressing", "quiescent" or "healed". No statistical analysis was made of the distribution of cases among these purely qualitative categories, but steadily progressive healing took place in response to both treatments. It is particularly noteworthy that none of the lesions revealed any signs of activity after 24 weeks' treatment, either with dapsone or with clofazimine.

TABLE 2

Histopathological findings in evaluable LL/LI patients at the beginning of and during treatment

\begin{tabular}{|c|c|c|c|c|c|c|c|c|}
\hline \multirow[t]{3}{*}{ Week } & \multicolumn{4}{|c|}{ Dapsone } & \multicolumn{4}{|c|}{ Clof azimine } \\
\hline & \multicolumn{2}{|c|}{ GI } & \multicolumn{2}{|c|}{ HI } & \multicolumn{2}{|c|}{ GI } & \multicolumn{2}{|c|}{$\mathrm{HI}$} \\
\hline & $n$ & $\overline{\mathbf{x}}$ & $n$ & $\bar{x}$ & $n$ & $\overline{\mathrm{x}}$ & $n$ & $\overline{\mathbf{x}}$ \\
\hline 0 & 18 & 0.46 & 18 & 5.2 & 20 & 0.53 & 20 & 5.3 \\
\hline 24 & 17 & 0.24 & 18 & 4.5 & 20 & 0.33 & 20 & 4.8 \\
\hline 48 & 13 & 0.16 & 13 & 3.6 & 12 & 0.27 & 12 & 4.3 \\
\hline Initial ranges & \multicolumn{2}{|c|}{$0.2-0.7$} & \multicolumn{2}{|c|}{$4.6-5.9$} & \multicolumn{2}{|c|}{$0.15-0.9$} & \multicolumn{2}{|c|}{$4.75-5.9$} \\
\hline $\begin{array}{l}\text { Regression coefficient, } \\
\quad b_{c}=\end{array}$ & \multicolumn{2}{|c|}{-0.012} & \multicolumn{2}{|c|}{-0.034} & \multicolumn{2}{|c|}{-0.008} & \multicolumn{2}{|c|}{-0.020} \\
\hline
\end{tabular}

Quantitative data on the improvement observed are listed in Table 2, which shows the mean values of the Granuloma Index (GI) and the Histopathological Index $(\mathrm{HI})$, the latter being the product of the individual $\mathrm{GI}$ and the $\mathrm{BI}$ at a given time. In both treatment groups, the extension of the granuloma within the dermis diminished linearly. Analysis of variance proved that the reduction was statistically significant. The same was the case with the HI.

As is evident from the gradient of the regression lines, determined by the three points of measurement, the thickness of granuloma diminished slightly more rapidly in response to dapsone than in response to clofazimine. This difference is statistically not significant.

\section{CLINICAL FINDINGS}

In 69 patients, the investigators came to a general conclusion about the clinical progress. On dapsone 27 patients improved, 6 were unchanged and 3 became worse (i.e. new lesions appeared during therapy). On clofazimine, 31 improved and 2 remained unchanged. As the improvement could not be quantified it was not amenable to statistical analysis.

A comparison of the body-weight before and during treatment of the LL/LI 
patients in both treatment groups revealed an average increase of $2.0 \mathrm{~kg}$ (from 50.4 to $52.4 \mathrm{~kg}$ ) after 24 weeks in the dapsone group and $4.0 \mathrm{~kg}(47.4$ to $51.4 \mathrm{~kg})$ after 18 weeks in the clofazimine group. Although the average body-weight of the patients in the clofazimine group was slightly lower than that of the dapsonetreated patients, it was never significantly different.

\section{SIDE EFFECTS}

Discolouration of the skin is regarded as a common side effect of clofazimine. Hypermelanosis of lesions has been observed as well as an extensive red discolouration. Although dapsone can also give rise to cutaneous pigmentation, especially of the lesions, there was nevertheless occasion to fear that it might occur more frequently in the patients treated with clofazimine and thus jeopardize the double-blind design of the trial.

TABLE 3

Frequency and localization of skin discolouration

\begin{tabular}{lrrrrrr}
\hline \multirow{2}{*}{ Localization } & \multicolumn{2}{c}{ Dapsone } & \multicolumn{2}{c}{ Clofazimine } & \multicolumn{2}{c}{ Total } \\
& abs. & $\%$ & abs. & $\%$ & abs. & $\%$ \\
\hline Lesions only & 2 & $(4.2)$ & 3 & $(6.5)$ & 5 & $(5.3)$ \\
Generalized & 8 & $(16.6)$ & 7 & $(15.2)$ & 15 & $(16.0)$ \\
Lesions and generalized & 3 & $(6.3)$ & 2 & $(4.3)$ & 5 & $(5.3)$ \\
Total & 13 & $(27.1)$ & 12 & $(26.0)$ & 25 & $(26.6)$ \\
Size of treated group & 48 & $(100.0)$ & 46 & $(100.0)$ & 94 & $(100.0)$ \\
\hline
\end{tabular}

In the total of 94 patients, altogether 25 instances of discolouration were recorded, the distribution of which is shown in Table 3. The times when this phenomenon was first reported were almost evenly spread over the entire duration of the trial in both treatment groups. Patients of darker hue (African) and of lighter hue (Chinese, European) were also equally represented in both treatment groups.

One may conclude that at least at this dose level, there is no significant difference between the two drugs in this respect. Since there was no clear-cut predominance of generalized discolouration in the group treated with clofazimine it may be inferred that this side effect was less pronounced than would have been expected at a daily dosage of, say, $100 \mathrm{mg}$.

Other side effects were observed in 10 of the 48 patients on dapsone and in 12 of the 46 on clofazimine. The nature and the distribution of these are shown in Table 4 . The side effects were usually mild and not always clearly related to the drug administered. Treatment had to be withdrawn on account of side effects in two cases receiving dapsone ( 1 rash, 1 anaemia) and two receiving clofazimine ( 1 rash, 1 gastric complaints).

\section{LEPRA REACTIONS}

During the 48-week trial, 47 of the 94 patients, i.e. exactly half of the whole series, suffered at least one reactional episode. There were about twice as many dapsone- as clofazimine-treated patients amongst those showing reaction. Table 5 illustrates these relations. The difference between the two treatment groups is statistically significant at the $95 \%$ probability level $\left(\chi^{2} 6.252\right.$, d.f. 2$)$. The 
TABLE 4

Kind and frequency of other supposed side effects

\begin{tabular}{lccc}
\hline Nature of side effect & Dapsone & Clofazimine & Total \\
\hline General (weakness, dizziness, headache) & 4 & 3 & 7 \\
Gastro-intestinal (abdominal pain, nausea) & 3 & 2 & 5 \\
Anaemia & 1 & 1 & 2 \\
Vascular (Oedema, Epistaxis, Phlebitis) & 4 & 3 & 7 \\
Pain (bone and joint pain, myalgia) & 2 & 2 & 4 \\
Epidermal (rash, pruritus) & 2 & 6 & 33 \\
Total of occurrences & 16 & 17 & 22 \\
Patients concerned & 10 & 12 & \\
\hline
\end{tabular}

TABLE 5

Patient population according to presence or absence of lepra reaction

\begin{tabular}{lccc}
\hline Patients showing & Dapsone & Clofazimine & Total \\
\hline ENL & 14 & 7 & 21 \\
Other reactions only & 16 & 10 & 26 \\
No reaction & 18 & 29 & 47 \\
Total & 48 & 46 & 94 \\
\hline
\end{tabular}

frequency and severity of ENL and all types of reaction including iritis, orchitis, stasis syndrome, panniculitis, acute exacerbation of lesions, or neural reactions, were higher in the dapsone-treated group than in the clofazimine-treated group. The frequency of reactive phases can vary enormously from one patient to the other and combinations are manifold. Because of this great complexity it is difficult to describe the events adequately. For example, the cumulative frequency of bouts of ENL while on dapsone (24 times in 14 patients) and on clofazimine (8 times in 7 patients) is depicted in Fig. 1.

The nature of the curve in this cumulative presentation, whether rising or horizontal, may be regarded as an indication of the stress imposed upon the treating and nursing personnel.

Seven patients ( 4 on dapsone, 3 on clofazimine) were withdrawn from the trial on account of lepra reactions. As a rule, however, the concomitant treatment given for the reactions (antimonials, chloroquine and in some cases steroids) sufficed to suppress the inflammatory processes.

\section{Discussion and Conclusions}

\section{THE RESULTS OF THE TRIAL}

The results presented here were obtained on a multicentric basis. Although the patients treated originated from very different countries and circumstances, they were nevertheless homogeneous in respect of their histological classification. Evaluation of the bacteriological and histopathological progress was strictly limited to LL/LI patients, whereas the assessment of side effects and lepra reactions included also the $\mathrm{BL}$ patients. 


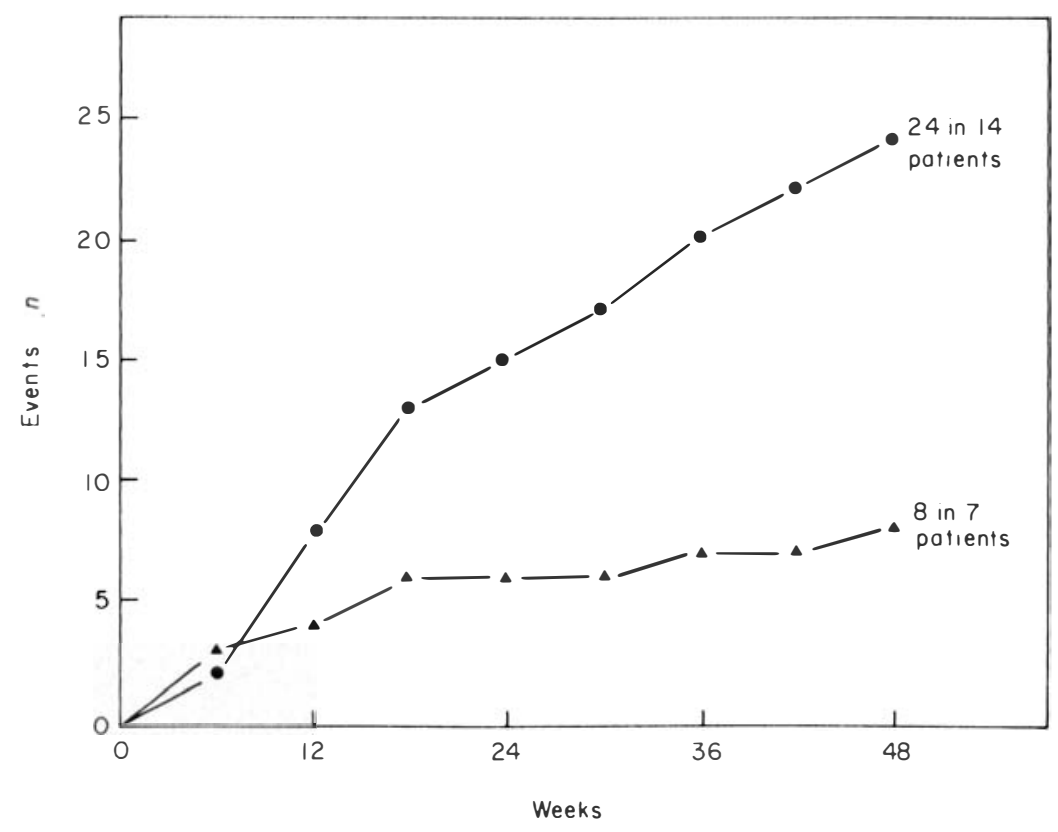

Fig. 1. Cumulative frequency of bouts of ENL while on dapsone $(\bullet-\bullet)(14 / 48$ patients) or clofazimine ( $\left.\boldsymbol{\Delta}_{-} \mathbf{\Delta}\right)(7 / 46$ patients).

Comparison of the results obtained in this study demonstrates, in a statistically sound manner, that low-dose therapy with both these agents elicited an almost identical short-term antibacterial effect. This was manifested by a decline in the MI, which approached zero after about 18 weeks' treatment. As was to be expected, there was little change in the BI up to the first year of treatment, and during this time fluctuations were noted in both groups. This factor was less pronounced in the GI and the HI: here the decline was almost linear, and there was no significant difference between the two treatments. From the clinical point of view also, the two groups appear to have made equal progress.

It should be borne in mind that the reason for administering low doses of dapsone was the hope of diminishing the incidence of lepra reactions. However, though Karat et al. (1969), found that the severity of ENL was diminished when dapsone was given in doses of only 35 or $10 \mathrm{mg}$ weekly, neither they, nor Leiker and Carling (1969) who administered $20 \mathrm{mg}$ weekly noted any difference in the incidence of reactions. In the present trial the incidence, severity and duration of lepra reactions were not noticeably less than would have been expected on high doses of dapsone. This applies especially to ENL. Compared with the clofaziminetreated patients, about twice as many patients on dapsone displayed ENL and, individually, their bouts of reaction were about twice as frequent. Reversal reactions, resulting histologically in a shift towards the other pole were too rare ( 3 on dapsone, 2 on clofazimine) to allow statistical analysis.

In the case of clofazimine the object of trying low-dosage treatment was to 
avoid, at least partly, the inconvenience of red discolouration. (The hypermelanosis which sometimes occurs with both sulphone and clofazimine therapy seems unavoidable.) The results clearly show that this complication, if present, was not a problem here, thus supporting the view that it is a dose-dependent phenomenon.

The conclusion therefore appears to be that clofazimine is superior to dapsone at the low dosage level, and for a limited period of time. It should be recommended in cases where treatment phases of this kind are indicated. No conclusions can be reached concerning the relative value of the two treatments over a period of more than one year. Although at the time when the present trial was initiated there were a number of reports favouring the use of low dose therapy the current view of many workers is that monotherapy at low dose over a long period invites the risk of bacterial resistance (Jacobson, 1973; Meade et al., 1973; Gelber et al., 1974). Although these reports all refer to sulphones, and although the minimal effective dose of clofazimine may be as low as about $7 \mathrm{mg}$ a day (Shepard, 1969) this objection probably has general application.

The original intention was that any BL patients would be used only for a study of the effect of clofazimine on reversal reactions. In the event there were scarcely any BL patients except those of the "histiocy tic" type (Ridley and Jopling, 1966) with few lymphocytes. It has since been observed that the response of these patients is similar to those of the LI group, and it has been proposed that with certain provisos they should now be graded as LI (Ridley, 1975). Consequently, there were few reversal reactions and the BL group could be disregarded for the bacteriological and histological evaluation. It is not recommended that true $\mathrm{BL}$ patients shoủld be included in this sort of trial. The dearth of such patients in this series is to the credit of the clinicians in selecting lepromatous patients.

\section{THE PROBLEMS OF THE MULTI-CENTRE METHOD}

Difficulties are always likely to arise in clinical trials conducted on a multicentric basis, unless virtually unlimited funds and resources are available to ensure that all organizational requirements are met. This double-blind study proved no exception. Loss of information and the long duration posed major problems of the sort familiar enough in therapeutic trials in any chronic disease.

There was no independent clinical observer, whose task it would have been to assess the clinical progress in a consistent manner. In a trial covering such a vast area as this one did, it is, however, difficult to achieve this ideal, as Waters et al. (1967) have already pointed out. In the present study, each investigator was impartial in so far as he had no knowledge of the treatments administered, and his statements were based mainly on the presence or absence of any marked or persistent deterioration in a patient's condition. Regular contact with an independent observer interested in the trial would certainly have afforded more encouragement and incentive to the investigators. Better communications would probably have helped to increase the volume of evaluable data and reduce the number of drop-outs. Under the circumstances, histology is the only approach that affords opportunity for uniform evaluation and assessment. As to the value of the methods used in this trial, there appears to be no doubt that this type of investigation can supply answers to preformulated questions, as long as they relate to measurable parameters or to the presence or absence of particular phenomena. 


\section{Acknowledgements}

The authors wish to express their indebtedness to the many collaborators named in the text for their patient cooperation and for their work which forms the basis of this study. We thank each one of them. We are most grateful also to Mrs Marian J. Ridley, London, for the histological processing, to Encik Bakhri, Sungei Buloh, for bacteriological assistance, to Mrs Marlene Jacot, Lausanne, for the most valuable secretarial help, and to Mr A. Kirkwood, Basle for translating the original manuscript. Our thanks are due to Dr J. Walter of the World Health Organization for his helpful comments.

\section{References}

Bliss, C. I. (1967) Statistics on Biology, Vol. 1. New York: McGraw-Hill Book Company.

Browne, S. G. (1965). B.663-Possible anti-inflammatory action in lepromatous leprosy. Lepr. Rev. 36, 9-11.

Browne, S. G. and Hogerzeil, L. M. (1962). B.663 in the treatment of leprosy. Preliminary report of a pilot trial. Lepr. Rev. 33, 6-10.

Gelber, R. H., Gooi, H. C., Waters, M. F. R. and Rees, R. J. W. (1974). The pharmacology of sulphetrone and its implications in sulphone resistant leprosy. Lepr. Rev. 45, 308-312.

Jacobson, R. R. (1973). Sulphone resistant leprosy: etiology, incidence and treatment in the United States (abstract). Int. J. Lepr. 41, 684.

Karat, A. B. A., Jeevaratnam, A. and Rao P. S. S. (1969). An open trial of low doses of dapsone in the management of lepromatous leprosy. Lepr. Rev. 40, 99-105.

Karat, A. B. A., Jeevaratnam, A., Karat, S. and Rao, P. S. S. (1970). Double-blind controlled clinical trial of clofazimine in reactive phases of lepromatous leprosy. Br. med. J. 1, 198-200.

Leiker, D. L. and Carling, D. (1969). Second trial of low dosages of DDS in lepromatous leprosy. Lepr. Rev. 40, 54-58.

Meade, T. W., Pearson, J. M. H., Rees, R. J. W. and North, W. R. S. The epidemiology of sulphone resistant leprosy (abstract). Int. J. Lepr. 41, 684.

Pearson, J. M. H. and Pettit, J. H. S. (1969). Chemotherapeutic trials in leprosy. 7. Trial of $50 \mathrm{mg}$ DDS twice weekly in the treatment of lepromatous leprosy. Int. J. Lepr. 37, 40-45.

Pettit, J. H. S. and Rees, R. J. W. (1967). Chemotherapeutic trials in leprosy. 4. Dapsone (DDS) in low dosage in the treatment of lepromatous leprosy. A demonstration pilot study. Int. J. Lepr. 35, 140-148.

Ridley, D. S. (1958). Therapeutic trials in leprosy using serial biopsies. Lepr. Rev. 29, 45-52.

Ridley, D. S. (1967). A logarithmic index of bacilli in biopsies. II. Evaluation. Int. J. Lepr. 35, 187-193.

Ridley, D. S. (1975). Histological classification and the immunological spectrum of leprosy. Bull. Wld Health Org. (in press).

Ridley, D. S. and Hilson, G. R. F. (1967). A logarithmic index of bacilli in biopsies. I. Method. Int. J. Lepr. 35, 184-186.

Ridley, D. S. and Jopling, W. H. (1962). A classification of leprosy for research purposes. Lepr. Rev. 33, 119-1 28.

Ridley, D. S. and Jopling, W. H. (1966). Classification of leprosy according to immunity. A five group system. Int. J. Lepr. 34, 255-273.

Ridley, D. S. and Waters, M. F. R. (1969). Significance of variations within the lepromatous group. Lepr. Rev. 40, 143-152.

Shepard, C. S. (1969). Minimal effective dosages in mice of clofazimine (B.633) and of ethionamide against Mycobacterium leprae. Proc. soc. exp. Biol. Med. 132, 120-1 24.

Tolentino, J. G., Rodriguez, J. N. and Abalos, R. M. (1971). Controlled drug trial of B.663 compared with DDS. Preliminary (48 week) report. Int. J. Lepr. 39, 738-741.

Waters, M. F. R. (1968). Chemotherapeutic trials in leprosy. 6. Pilot study of the riminophenazine derivative B.663 in low dosage ( $100 \mathrm{mg}$ twice weekly) in the treatment of lepromatous leprosy Int. J. Lepr. 36, 391-399.

Waters, M. F. R. and Rees, R. J. W. (1962). Changes in the morphology of Mycobacterium leprae in patients under tre atment. Int. J. Lepr. 30, 266-277.

Waters, M. F. R., Rees, R. J. W., Sutherland, I. (1967). Chemotherapeutic trials in leprosy. 5. A study of methods used in clinical trials in lepromatous leprosy. Int. J. Lepr. 35, 311-335. 